\title{
The Multiple Landscapes into Which One Figures
}

The rock hammer on the pillow is a gift.

Sugar yourself with cinnamon and grind the rosewood stakes to dust.

The hive is a dried nosegay.

Do not desecrate

but chisel the footing so the shrine comes apart

in clumps of rock until there is no outward sign

this house was ever visited upon.

No telltale

sword or red apple.

Our resident saint graces the curb, brittle baby's breath on chipped marble. Off her profile the heat shaves corrugated noon while insects pursue her skirt's Greek key.

In the photogenic present it's easy to tell the small wings from the leaves, jasmine vine from butterfly stalk.

All along the coast coralscapes of jalousie and terrazzo rise.

We decide you are shattered enough to shatter a little further. 